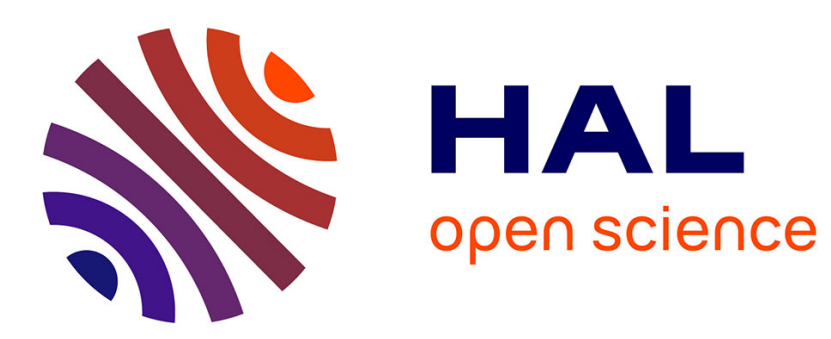

\title{
Microwave permittivity extraction of individual biological cells submitted to different stimuli
}

\author{
Amel Zedek, David Dubuc, Katia Grenier
}

\section{To cite this version:}

Amel Zedek, David Dubuc, Katia Grenier. Microwave permittivity extraction of individual biological cells submitted to different stimuli. IEEE International Microwave Symposium 2017, Jun 2017, Honolulu, United States. 4p. hal-01597796

\author{
HAL Id: hal-01597796 \\ https://hal.laas.fr/hal-01597796
}

Submitted on 28 Sep 2017

HAL is a multi-disciplinary open access archive for the deposit and dissemination of scientific research documents, whether they are published or not. The documents may come from teaching and research institutions in France or abroad, or from public or private research centers.
L'archive ouverte pluridisciplinaire HAL, est destinée au dépôt et à la diffusion de documents scientifiques de niveau recherche, publiés ou non, émanant des établissements d'enseignement et de recherche français ou étrangers, des laboratoires publics ou privés. 


\title{
Microwave permittivity extraction
}

\section{of individual biological cells submitted to different stimuli}

\author{
Amel ZEDEK, David DUBUC, Katia GRENIER \\ LAAS-CNRS, University of Toulouse, CNRS, Toulouse, France
}

\begin{abstract}
This paper describes, for the first time, the relative permittivity extraction of cells in their culture medium submitted to different stimuli by using a microwave biosensor, specifically developed to analyze single cells. The sensitive part of the device is constituted by a $5 \mu \mathrm{m}$ coplanar gap, over which the cell is blocked by a mechanical trap. It allows to obtain the capacitive and conductive contrasts of a cell. Electromagnetic simulations where the cell (sphere) permittivity is tuned permit to define fitted calibration curves linking capacitive and conductive contrasts to the real and imaginary parts of the relative permittivity. Measurements are performed on various cells (in their culture medium) after different environmental stimuli in order to induce various biological stresses altering the cell state. Results show that this non-invasive technique, including the developed proper de-embedding post-process, provides the intrinsic dielectric image of single biological cells, which then reveals their biological state.

Index Terms - Microwave dielectric spectroscopy, biosensor, coplanar waveguide, single cell analysis, biological cells, microfluidic.
\end{abstract}

\section{INTRODUCTION}

One of the main challenges in biology, and more specifically in cancer research, is to evaluate the cell behavior according to any extracellular stimulus. Researchers in these domains are very interested in all method that could inform them about cell reactions and kinetics [1].

In biological and medical laboratories, the common methods to analyze cells are optically-based with essentially microscopes and flow cytometers. These techniques are very precise and efficient due to the use of specific markers and fluorophores to highlight the cells processes. It imposes however to add chemicals on or inside cells, which may interact with other molecules. Moreover, preparing the samples for each experiment is expensive and timeconsuming, and it may affect the cells, which cannot be reused afterwards. In complementarity, the ability of analyzing cells as a complex biological system has considerably increased during the last two decades [2].

As the number of combinations between samples, reagents and assays is rising, it has become necessary to develop new approaches to understand and exploit this complexity.

One of the approaches to address this complexity has been to reduce the scale of the experiments with microfluidics and laboratories on a chip.

They have indeed been developed and used to realize and improve a certain number of biological tests with small amounts of reagents in microchannels (with few $\mu$ liters) [3].
To complement cellular analysis, mechanical and electrical techniques are also under development. Among them, microwave dielectric spectroscopy exhibits attractive features [4], such as no direct contact required, intracellular measurement, in liquid, especially compatible with high ionic content of traditional cell culture medium, non-invasivity, as it does not require any exogenous molecule to analyze cells. This method may also respond to the need of monitoring biological processes over time. This technique has already been developed to analyze both cells suspensions and individual cells. Up to now, single cells have been characterized in the microwave range through $\mathrm{S}$ parameters measurements $[5,6]$ and the capacitive and conductive contrasts between cells in medium and medium alone $[7,8]$.

To go further in the microwave dielectric characterization of single cells, we present in this paper the extraction of the relative permittivity of individual cells submitted to different environmental stimuli, thermal and chemo-induced ones notably. After a rapid introduction of the microwave and microfluidic biosensor used for the study, employed cells and stimuli are described. Microwave measurements are then given for different cells types. Next section is then dedicated to the permittivity extraction of individual cells.

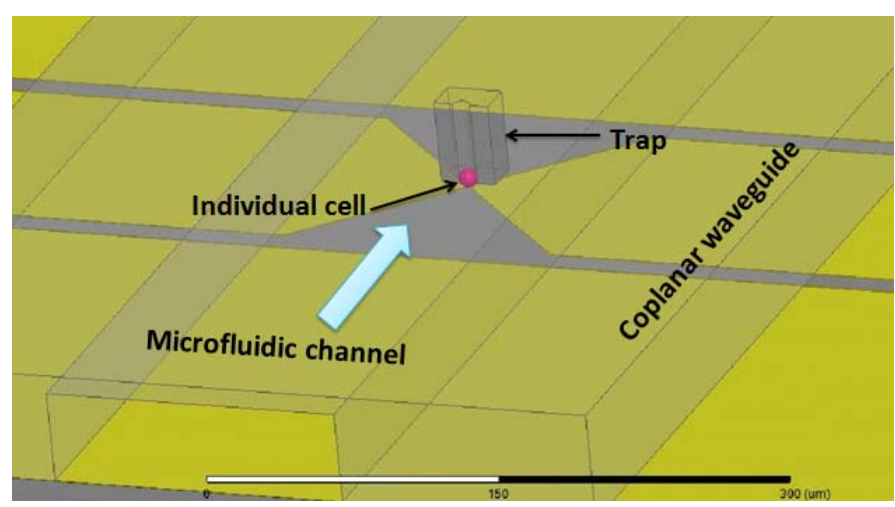

Fig. 1. Schematic view of the microwave biosensor, which includes a $5 \mu \mathrm{m}$ capacitive gap in coplanar waveguide with a microfluidic channel placed on top; the cell is blocked due to a mechanical trap.

\section{SINGLE CELL MEASUREMENTS}

In this section, the biosensor architecture is briefly given and followed by a rapid description of employed cells, which 
are submitted to different stimuli. Their microwave characterization is then performed from $40 \mathrm{MHz}$ to $40 \mathrm{GHz}$.

\section{A. Biosensor architecture}

The biosensor is composed of two main parts, one dedicated to the microwave characterization and a second devoted one to the fluid flow and particle trapping, as indicated in Fig. 1.

The microwave part consists in a coplanar waveguide realized in gold, which presents a $(w, s)$ of $(150,15) \mu \mathrm{m}$, with a capacitive gap placed in its center. This gap exhibits a width of $5 \mu \mathrm{m}$ for optimized sensitivity [8].

A microfluidic channel allows the flow of the biological liquid under test; this microchannel has in its center a hydrodynamic trap, which enables to block an individual particle just on top of the capacitive gap. The fluidic channel permits to keep the biological sample in liquid for microwave characterization.

One a particle is trapped, the electrical signals change due to the permittivity of the particle under test.

\section{B. Experimental protocol}

THP1 cells studied in this paper correspond to a human leukemia monocytic cell line. These circulating cells are usually employed by biologists for cancer studies. THP1 are cultivated at $37^{\circ} \mathrm{C}$ with $5 \%$ of $\mathrm{CO}_{2}$ in an incubator in their culture medium, which is composed of RPMI(Roswell Park Memorial Institute medium) supplemented by $10 \%$ SVF (Foetal Calf Serum) and antibiotics.

The cells are measured after different stimuli.

- The first sample is made of living cells in suspension in their culture medium, with no stress applied.

- The second sample corresponds to cells, which have been submitted to a thermal stress. The cells in their culture medium are heated at $50^{\circ} \mathrm{C}$ for 10 minutes.

- The third sample is composed of chemo-induced permeabilized THP1 cells. The chemical stimulus is performed with a detergent called saponin at the concentration of $0.04 \%(\mathrm{w} / \mathrm{v})$. Saponin creates micrometric holes in the cell membrane leading to cell death.

These three different cellular samples are then dielectrically characterized.

\section{Microwave measurements}

Microwave measurements are performed in two steps. The first one consists in measuring the biosensor loaded with the RPMI culture medium only, whereas the second one with trapped individual cells in culture medium. From $\mathrm{S}$ parameters, capacitive and conductive contrasts between the cell in its medium and the medium itself are then calculated [9] and plotted in Fig.2. The zero line corresponds to the reference, the sensor loaded with the medium only. The other curves in Fig. 2 (a) and (b) represent the mean value for both capacitive and conductive contrasts versus frequency of the different cells samples, respectively. Each spectrum corresponds to the average of the measurement of 3 individual cells for each cells sample.

The insert of Fig. 2 (a) presents a photography of the central part of the sensor when loaded with a cell in the culture medium.

The results show that the capacitive and conductive signatures of the cells are different depending on the nature of the applied stimulus: no stimulus, saponin stimulus and heating stimulus. Fig. 2 also reveals that maximal contrasts are reached at $5 \mathrm{GHz}$ and $30 \mathrm{GHz}$ for capacitive and conductive contrasts respectively. The next section will consider these two selected frequencies for the cellular permittivity extraction.

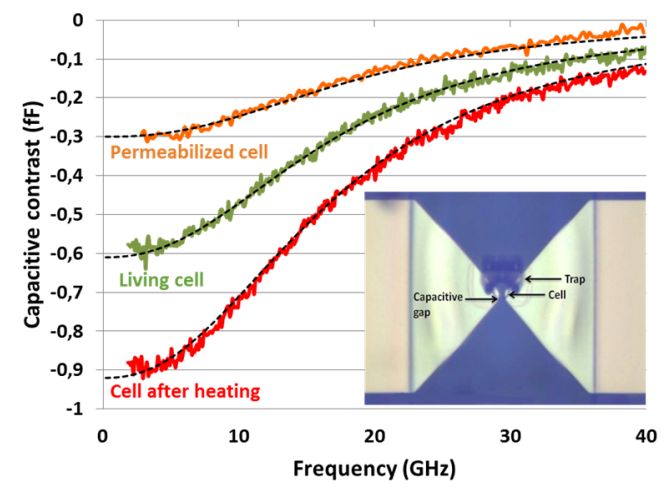

(a)

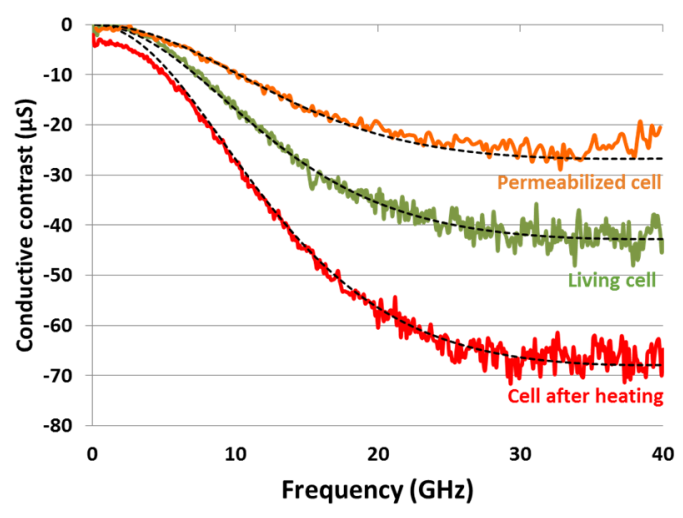

(b)

Fig. 2. Mean values for capacitive and conductive contrasts of individual cell submitted to no stress, thermal stress $\left(50^{\circ} \mathrm{C} 10 \mathrm{~min}\right)$, and chemo-induced permeabilization, in their culture medium. 


\section{SINGLE CELL PERMITTIVITY EXTRACTION}

\section{A. Extraction procedure}

The dielectric permittivity and loss tangent of a sphere with a $10 \mu \mathrm{m}$ diameter to simulate a single cell are tuned on ANSYS ${ }^{\circledR}$ HFSS software. As the reference for the 'contrasts' definition, we consider a data base of dielectric properties of the culture medium previously characterized in the research group. From these electromagnetic simulations, we extract the capacitive and conductive contrasts using the same posttreatment used for the measurements. Fig. 3 gathers the simulated results and outlines the linear relationships between (a) the capacitive contrast with the real part of the sphere permittivity (at $5 \mathrm{GHz}$ ), and (b) the conductive contrast with the imaginary part of the sphere permittivity (at $30 \mathrm{GHz}$ ).

As indicated in Fig. 3, the simulated results have been linearly fitted using the least-squares method. The equations (1) and (2) shows the resulting linear relationships between the contrasts and the relative permittivity values where $\Delta \mathrm{C}$ and $\Delta \mathrm{G}$ are in $\mathrm{fF}$ and $\mu \mathrm{S}$ respectively.

$$
\begin{aligned}
& \Delta \mathrm{C}_{5 \mathrm{GHz}}=0.037 *(\varepsilon '-77.6) \\
& \Delta \mathrm{G}_{30 \mathrm{GHz}}=3.76 *\left(\varepsilon^{\prime},-31.8\right)
\end{aligned}
$$

(a)

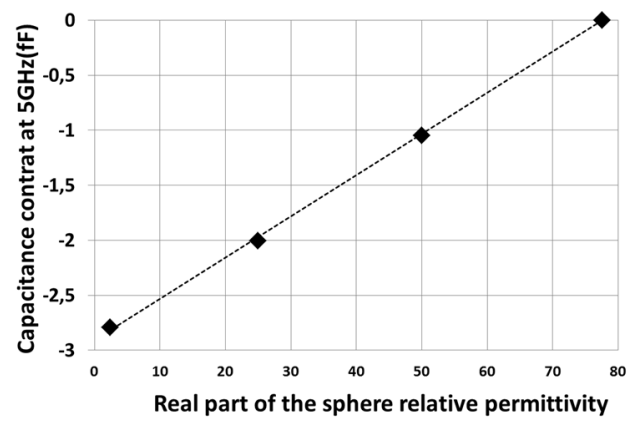

(b)

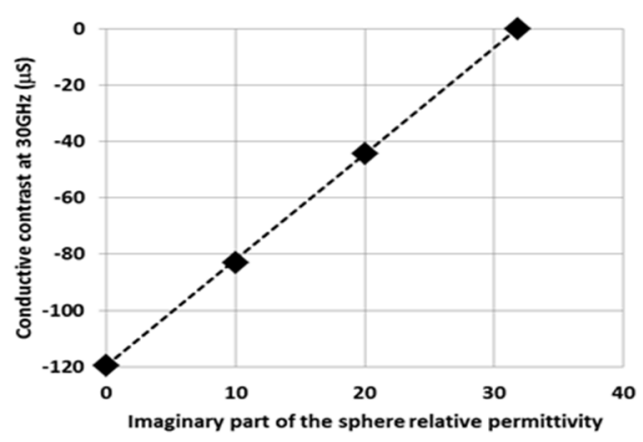

Fig. 3. Plots of (a) capacitive contrast versus $\varepsilon$ ' at $5 \mathrm{GHz}$ and (b) conductive contrast versus $\varepsilon$ " at $30 \mathrm{GHz}$ of a single sphere featuring different permittivity values.

In equations (1) and (2), the 77.6 and 31.8 values correspond to the real part at $5 \mathrm{GHz}$ of the relative permittivity of the cultured medium and its imaginary part at $30 \mathrm{GHz}$. These two values have been forced during the least-square procedure to assure null values of both $\Delta \mathrm{C}$ and $\Delta \mathrm{G}$ when pure culture medium is filled in the microfluidic channel.
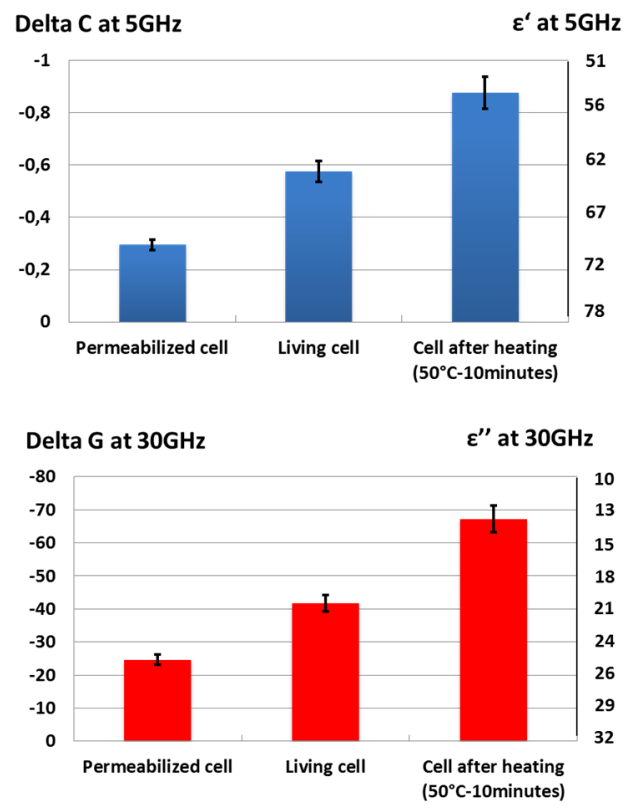

Fig. 4. Average values of the contrasts of different cells states measurements and their dielectric permittivity correspondence obtained with the plots fit of equations (1) and (2).

Fig. 4 presents the dielectric level on both $\Delta \mathrm{C}$ and $\varepsilon$ ' at $5 \mathrm{GHz}$ and $\Delta \mathrm{G}$ and $\varepsilon "$ at $30 \mathrm{GHz}$ for the three set of cells (in their culture medium) depending on the different environmental stimuli submitted to the cells. The secondary (right) axes in Fig. 4 as well as Table 1 present the extracted from equations (1) and (2) -real and imaginary parts of the relative permittivity at $5 \mathrm{GHz}$ and $30 \mathrm{GHz}$ of a living cell, a permeabilized cell and a cell after heating stress.

The highest dielectric values (for both real and imaginary parts) are reached for the permeabilized cells. This cell's membrane permeabilization translate indeed to equilibrate the intracellular and extracellular medium and consequently to vanish the capacitive and conductive contrasts. As a consequence, as both contrasts rise, the relative permittivity tends to reach the culture medium ones (see table I). Conversely, cells after heating feature lower dielectric values. Beyond the mechanisms beside this decrease, which are under evaluation, these results highlight that, depending on the environmental stimulus (chemical with saponin or thermal), the cells die in a different manner (and reach different biological states) that is revealed by the dielectric state of the cells. 
Table 1. Dielectric properties of single THP1 living cell with no stress, after thermal stress, and after permeabilization.

\begin{tabular}{|l|c|c|}
\hline & $\varepsilon^{\prime}$ at $5 \mathrm{GHz}$ & $\varepsilon^{\prime \prime}$ at $30 \mathrm{GHz}$ \\
\hline Living cell & 62,3 & 20,7 \\
\hline Permeabilized cell & 69,8 & 25,2 \\
\hline Cell after heating & 54,2 & 13,9 \\
\hline
\end{tabular}

\section{CONCLUSION}

To conclude, we present for the first time the extraction of the complex permittivity of individual biological cells in liquid medium. Based on measured capacitive and conductive contrasts of individual cells and electromagnetic simulations, single cell permittivity has been extracted at $5 \mathrm{GHz}$ and 30 $\mathrm{GHz}$ for real and imaginary parts of cell permittivity. Different stimuli, such as thermal stress or chemo-induced permeabilization, have been applied and lead to different dielectric states of cells.

\section{ACKNOWLEDGEMENT}

This work was supported in part by a French ITMO Cancer grant of the Plan Cancer 2014-2019 (grant $\mathrm{n}^{\circ}$ PC201522) and in part by LAAS-CNRS micro and nano technologies platform, member of the French RENATECH network.

\section{REFERENCES}

[1] D. Di Carlo, L. P. Lee, "Dynamic single-cell analysis for quantitative biology," Anal. Chem., pp. 7918-7925, Dec. 2006.

[2] S. Maulik et al., Molecular Biotechnology: Therapeutic Applications and Strategies. John Wiley \& Sons, 1997.

[3] G. M. Whitesides, "The origins and the future of microfluidics," Nature, vol. 442, $\mathrm{n}^{\circ}$ 7101, pp. 368-373, Jul. 2006.

[4] K. Grenier, D. Dubuc, T. Chen, F. Artis, T. Chretiennot, M. Poupot, and J. J. Fournié, "Recent Advances in MicrowaveBased Dielectric Spectroscopy at the Cellular Level for Cancer Investigations," IEEE Trans. Microw. Theory Tech., vol. 61, $\mathrm{n}^{\circ}$ 5, pp. 2023-2030, May 2013.

[5] Y. Ning, C. Multari, X. Luo, C Pelgeo, X. Cheng, J. Hwang, A. Denzi, C. Merla, F. Apolloni, and M. Liberti. "Broadband Electrical Detection of Individual Biological Cells," IEEE Trans. Microw. Theory Tech., vol. 62, n 9, Sep 2014, pp. 19051911.

[6] Y. Yang, Z. Hanqiao, Z. Junjie, W, Gaoyan, T. Tzuen-Rong, X. Xiangchun, H. Kama, and W. Pingshan "Distinguishing the viability of a single yeast cell with an ultra-sensitive radio frequency sensor," Lab.on a Chip, 2010, pp. 553-555.

[7] T. Chen, F. Artis, D. Dubuc, J. J. Fournié, M. Poupot, and K. Grenier, "Microwave biosensor dedicated to the dielectric spectroscopy of a single alive biological cell in its culture medium," in 2013 IEEE MTT-S International Microwave Symposium Digest (MTT),Jun 2013, pp. 1-4.

[8] W. Chen, D. Dubuc, K. Grenier., "Microwave dielectric spectroscopy of a single biological cell with improved sensitivity up to $40 \mathrm{GHz}$," in IEEE MTT-S International Microw. Symp. Dig., May 2015, pp. 1-3.
[9] T. Chen, D. Dubuc, M. Poupot, J. J. Fournie, et K. Grenier, "Accurate Nanoliter Liquid Characterization Up to $40 \mathrm{GHz}$ for Biomedical Applications: Toward Noninvasive Living Cells Monitoring," IEEE Trans. Microw. Theory Tech., vol. 60, $\mathrm{n}^{\circ}$ 12, pp. 4171-4177, Dec. 2012. 